\title{
Pushing the profession: how the news media turned patient safety into a priority
}

\section{L Millenson}

The problem of patient safety has been repeatedly identified in the medical literature since the mid 1950s, but regular revelations about patient deaths and injuries resulting from treatment have had almost no effect on the actual practice of medicine. Only very recently has the medical profession made a systematic effort to reduce or eliminate the many preventable deaths and injuries that occur in hospitals each year. This review traces the diffusion of innovation in medical error reduction to the public shaming of the profession that occurred as a result of stories that appeared in the news media. The focus is on the USA, but news stories about patient safety are sparking a similar process throughout the western world.

M L Millenson, Visiting Scholar, Institute for Health Services Research and Policy Studies,

Northwestern University, Evanston, Illinois, USA

Correspondence to: M L Millenson, 2735 Fort Sheridan Avenue, Highland Park, IL 60035, USA;

m-millenson@

northwestern.edu

Accepted for publication 7 January 2002
$\mathrm{T}$ he importance of an external stimulus in changing ingrained thinking is well established. As Thomas Kuhn demonstrated in his landmark 1962 book "The structure of scientific revolutions", even scientists nominally committed to responding to objective evidence actually tend to ignore findings that contradict what they already believe. Altering a paradigm-a pattern of thinking-is traumatic and disruptive, necessitating "the community's rejection of one timehonored scientific theory in favor of another incompatible with it". ${ }^{1}$

Although the problem of patient safety has repeatedly been identified in the medical literature since the mid $1950 \mathrm{~s}^{2}$ the regular revelations about patient deaths and injuries resulting from treatment have had almost no effect on the actual practice of medicine. The traditional medical paradigm discouraged action in two powerful ways. Firstly, some non-specific level of inadvertent patient harm was accepted as unavoidable, thereby obviating any effort to eliminate it. Doctors were well intentioned and trying their best - "after all, nobody wants to kill a patient" ${ }^{\prime 3}$ but the technological complexity of modern medicine nonetheless resulted in "accidents, risks and dangers . . . to which, with best intent and most correct practice, we must occasionally subject our patients". ${ }^{4}$

Secondly, if a patient injury or death could not be classified as unavoidable, the clinician associated with that harm was stigmatised as negligent or incompetent. This reaction both discouraged the reporting of errors-which persistently minimised the apparent scope of the problem-and made it appear that errors that were reported were easily correctable by disciplining the "bad" clinicians who caused them.

Paradigms, wrote Kuhn, change only when the defenders of the old ways of thought can "no longer evade anomalies that subvert the existing tradition". As this article will show, it was the mirror held up to the profession by news media coverage that finally penetrated the selfprotective shell of rationalisations, subverted the old paradigm, and prompted the current effort to develop a systems orientated patient safety approach.

\section{HISTORY OF THE ROLE OF JOURNALISM IN PATIENT SAFETY}

The term "journalist" covers a wide spectrum of practitioners. Tabloid-type chroniclers of fluff and celebrity are renowned for their fleeting acquaintance with facts. Local television news often seeks the sensational and violent, grabbing ratings with the maxim: "If it bleeds, it leads". Even the traditional news media are fond of warning of the unavoidable distortion caused by journalism's inherent limits of space and time to tell a story. The closer you are to an event, the saying goes, the less likely you are to believe the version of it you read in the newspapers or see on television.

Still, while journalistic practice may too often deviate from theory, there remains a fierce commitment among traditional journalists to truth in reporting. Some truths can be footnoted; others, no less true, require a different kind of documentation. Like academics, who are adjured to write what they can demonstrate, traditional journalists are told never to accept any statement as factual that cannot be verified from more than one source. As the editors at the legendary City News Bureau of Chicago admonished their charges in a famous dictum: "If your mother says she loves you, check it out".

In a 1982 essay entitled "The Virtuous Journalist", Kirkhorn compared the role played by journalism in society with the role played by other "truth seeking" professions. He wrote:

"Journalism is not art, it is not science; neither is journalism scholarship, although the accomplishments of journalists, purposeful and accessible, often outdo the investigations of scholars.... [The virtuous] journalist ought to assume responsibilities not normally associated with journalism: witness, moral and intellectual arbiter, finder of truths ... agents of social redemption or social cohesion, if only as society's rememberers.".5

Until journalists "remembered" patient safety, it was an issue that society had forgotten and the profession had largely relegated to the pages of medical journals. After World War II a quantum leap in the ability of medicine to do good was 
accompanied by a corresponding increase in the ability to do harm. Studies of the impact of medical errors began to appear regularly. Two of the most comprehensive-those of Don Harper Mills (based on records of California hospitals in 1974) and the Harvard Medical Practice Study (based on records of New York State hospitals in 1984)-reached similar conclusions about the enormous magnitude of the problem, despite being separated by a continent in distance and a decade in time. ${ }^{67}$ Both studies, by their own admission, were motivated primarily by economic and legal concerns, not clinical onesthat is, doctors were worried about the fast rising cost of malpractice insurance. Neither the Mills nor the Harvard study, however, led to any substantial change in medical practice.

The strength and durability of professional complacency was highlighted in two articles in JAMA in December 1994. While the articles did not explicitly attempt to deal with any nations other than the United States, their conclusions nonetheless reflected the prevailing paradigm of the profession throughout the western world. "It is curious ... that high error rates have not stimulated more concerns and efforts at error prevention", wrote Lucian L Leape, a physician researcher at the Harvard School of Public Health, in an article entitled "Error in medicine". "Although error rates are substantial, serious injuries due to errors ... are perceived as isolated and unusual events-outliers." ${ }^{8}$

An accompanying commentary by Harvard colleague David Blumenthal agreed. "Concerning medical error and its prevention, the profession has, with rare exceptions, adopted an ostrich like attitude .... Mistakes have been treated as uncommon and atypical, requiring no remedy beyond the traditional .... [But a] large and growing collection of literature demonstrates that physicians' approaches to the management of medical error do not work well enough." ${ }^{9}$

It was no coincidence that this challenge to the prevailing paradigm appeared in the JAMA issue published just before Christmas; the editor George Lundberg hoped reporters in a relaxed holiday mood would pay little attention to the topic. "I wanted to publish the paper for the profession, but feared that I would lose my job if the public media hit hard on it", Lundberg confessed nearly six years later. ${ }^{10}$

Lundberg's fear that physicians would react with scalp hunting rather than soul searching was well founded. To cite just one example, Loyal Davis, a regent of the American College of Surgeons, was nearly expelled from Chicago's medical society in the 1950s after honestly answering a reporter's question about the prevalence of fee splitting. The society's outraged ethics committee voted to boot out Davis for publicly besmirching the profession's good name. The society dropped expulsion proceedings only after scathing editorials from the city's newspapers. ${ }^{11}$

Unfortunately for Lundberg, a reporter for National Public Radio (NPR) in Boston did notice the Leape article, which deliberately put the death toll from mistakes into catchy sound bite form: "Two 747s crashing every three days". The resulting NPR story caught the attention of The Washington Post whose subsequent article on the death toll from medical errors resulted in national attention by other news outlets. Lundberg's apprehension about his colleagues' reaction proved prescient.

"Hate mail began pouring in. I was accused of being on the side of the lawyers, a damned turncoat and traitor to the cause. An intense lobbying campaign to get rid of me began. I withstood the firestorm largely because James Todd was still executive vice president of the $A M A$. He understood the information and knew it was correct, so he deflected the criticism, pointing out that JAMA was editorially independent while also being a moneymaker for the AMA." ${ }^{10}$

Todd may have known the information was correct, but AMA leaders were not about to say so publicly. In early 1995 a seeming epidemic of errors erupted among the nation's hospitals. In Grand Rapids, Michigan a surgeon performing a mastectomy on a 69 year old patient removed the wrong breast; a
New York woman died when a doctor mistook her dialysis catheter for a feeding tube and ordered food to be pumped into her abdomen; and in a series of incidents at Tampa's University Community Hospital, a 51 year old diabetic had the wrong foot amputated, a 73 year old retired electrician died when a therapist mistakenly disconnected his ventilator, and a female patient underwent arthroscopic surgery on the wrong knee.

These high profile mistakes garnered intense coverage ranging from tabloid television shows to the editorial page of the Wall Street Journal. The coverage coincided with an AMA campaign to persuade a new Republican dominated Congress to approve "tort reform" limiting physicians' malpractice liability. An alarmed AMA launched an artful public relations counteroffensive that the author has deconstructed below.

"There are more than nine million physician/patient encounters every day in America," wrote AMA president Robert McAfee to the editors of some 200 newspapers." [Translation: A denominator that lumps outpatient sore throats with inpatient surgery immediately lowers the error rate.] "An extraordinarily high percentage are positive." [Translation: Physicians already perform better than anyone might reasonably expect.] "Some are miraculous. But isolated and sometimes egregious mistakes also occur." [Translation: Surely most patients would risk a few "isolated" mistakes in return for "some" miracles. $]^{12}$ Advice columnist Ann Landers printed a version of the same letter from Todd.

The AMA's reference to "isolated" mistakes, however, not only contradicted information in its flagship peer reviewed journal; it also contradicted an AMA scientific committee report to the AMA board less than a year earlier. That report concluded:

"Medication errors ... are not rare events ... and they compromise the confidence of patients and the general public in the health care system. Fortunately, most medication errors are preventable."13

This was a contradiction that eluded journalists, who focus on current controversy rather than historical context. Nonetheless, some senior AMA officials realised that the organisation's stance was ultimately untenable. As the chances of enacting tort reform faded, AMA attorney Martin J Hatlie, whose responsibilities including professional liability, persuaded the AMA board that it had to be proactive and he was given permission to form a National Patient Safety Foundation (NPSF) (M J Hatlie, personal communication, 17 January 1997).

\section{THE PROFESSION BEGINS TO CHANGE}

The NPSF was unveiled to the public at a conference held in Palm Springs, California in October 1996. The AMA and the Joint Commission on Accreditation of Healthcare Organizations-whose board is dominated by representatives of the AMA and the American Hospital Association (AHA)used the conference to publicly embrace Leape and other long time critics of hospital safety. Talk of "isolated" errors, "good intentions", and "bad" clinicians was conspicuously absent.

"Although experts agree that the error rate in medicine remains extremely low, now even staunch tort reform advocates say it's time to acknowledge that medical mistakes happen - are even common-and to find answers rather than seek culprits", explained a page 1 story in the AMA run newspaper American Medical News. ${ }^{14}$ The NPSF formally began its work in early 1997.

The public pressure that helped alter AMA attitudes was ultimately made possible by prior scandals that had eroded the post-war trust in the profession. In the years immediately after the war, press coverage consisted largely of a dutiful chronicling of scientific progress-the so-called "medical miracle" beat. Journalists could be as forgiving towards the profession as it was towards itself, as illustrated by the tolerant tone of a 1954 Fortune article: 
"The physician, after all, is organized into a guild whose rules require mutual back scratching and forbid face clawing .... [But] so long as they do not violate guild rules and name names, they will even talk about the occasional incompetence and rascality in their profession." 15

But by the mid1960s, with public scepticism about all established institutions increasing, respectful coverage of "miracles" was supplemented by more tough minded inquiries. In 1966 journalist Martin Gross's "The doctors" estimated that two million unnecessary operations were performed annually. Five years later surgeon "Lawrence Williams"writing under a pseudonym to protect himself from collegial retaliation-produced an insider's guide to mercenary medicine entitled "Unnecessary surgery". That same year Ralph Nader formed the Public Citizen Health Research Group, giving the consumerism movement a beachhead in health care. The group's first (and current) executive director, physician Sidney Wolfe, soon became a favourite "on the record" source for journalists and a regular witness at Congressional hearings on medical misdeeds. As a small number of physicians began to publicly break ranks with the "mutual back scratching" of the guild, outside pressure started to push the profession to improve care significantly in ways that internal discussions alone had failed to do.

Unnecessary tonsillectomies, for example, had been harshly condemned in the medical literature since the 1950s. However, the profession did not act to limit this common (and lucrative) procedure until public scandal and Congressional hearings on the avoidable deaths of children forced the issue in the early 1970s. This marked the first time that Congress had challenged the profession on clinical grounds.

In the 1980s a television exposé of anaesthesia accidents led to the formation of a special patient safety committee by the American Society of Anesthesiologists. In addition to this public shaming, an economic motive-rising malpractice premiums-provided an extra sense of urgency. ${ }^{16}$ Also in the 1980s, the death of Libby Zion, daughter of New York Times reporter Sidney Zion, led first to a public scandal about the work hours of often sleep deprived hospital residents and then to landmark legislation in New York State designed to limit those hours. The New York legislation became a model for similar limits nationwide.

\section{A DEATH WHOSE IMPLICATIONS COULD NOT BE AVOIDED}

The events leading to the newfound prominence of patient safety in the 1990s followed a similar trajectory. On 23 March 1995 a page 1 article in the Boston Globe related the tragic tale of a young mother with breast cancer who was betrayed in her fight against the disease. Under a headline reading "Doctor's orders killed cancer patient", veteran science reporter Richard A Knox wrote:

"When 39 year old Betsy A Lehman died suddenly last December 3 at Boston's Dana-Farber Cancer Institute, near the end of a grueling three-month treatment for breast cancer, it seemed a tragic reminder of the risks and limits of high-stakes cancer care. In fact, it was something very different. The death of Lehman, a Boston Globe health columnist, was due to a horrendous mistake; a massive overdose of a powerful anti-cancer drug that ravaged her heart, causing it to fail suddenly just as she was preparing to go home to her husband and two young daughters. The error was discovered only last month by Dana-Farber clerks [during a routine review of records], not [by] clinicians. Dana-Farber officials still have no explanation for how such a thing could have happened, ascribing it merely to 'human error'."'17

Because of an ambiguously worded protocol, a dose of cisplatin meant to be given over a 4 day period was instead infused into Lehman each day for 4 days. Another patient with breast cancer given a similar overdose suffered irreversible heart damage. Dana-Farber was one of the country's most prominent cancer institutions; the story of Lehman's death

\section{Box 1 A heartfelt message}

As only one of the thousands upon thousands of family members made to struggle over the loss or disabling of a loved one due to a slip in the hands of our healers, I applaud the convening of a national symposium on the crucial issue of patient safety. That this still elusive goal may be advanced through partnerships and sharing of knowledge is commendable and long sought.

But may I appeal to you to pause for a moment, if you will, in your important task. For in the wings outside your busy meeting rooms may be heard the murmurings of patients gone now due to fatal medical error, or harmed by a medical system they trusted. They are ones absent from your nationwide gathering devoted to the welfare of patients. Among them is my young brilliant daughter suddenly lost through a team-blind medication error 6 years ago at the Dana Farber Cancer Institute in Boston. Ironically, Betsy, the mother of two, was a widely read Boston Globe consumer health columnist.

Modern medical care saves the lives of sick and hurting people every day. But patients and caregivers alike know of the need to balance the extremely powerful-yet often exquisitely fragile efforts - in the struggle against death and suffering. The challenge is to make it safer for patients coming to have their lives saved or to be healed.

To rely on blame as a curative for error overlooks a duality of interests in our healthcare facilities. Unfortunately, our family was made to witness all too closely the tension. Your coming together at this symposium, I believe, is an acknowledgement that patient safety must be utmost and constant, both ingrained into the system you seek to strengthen and into caring hearts. Systems in our healthcare facilities devised to maximise patient safety are vital, but so is the responsibility of each individual caretaker.

Still, we are left with a troubling question for both patient and caring professional alike-that is, whether today's business-like healthcare facilities may be turning patients into customers. If so, let us not find ourselves in our concern for safety constrained to caution "let the customers beware". I applaud the new journal Quality and Safety in Health Care and hope it will keep the voice of the patients and their families heard.

Mildred K Lehman

Brookline, Massachusetts, USA

[Adapted with permission from Mrs Lehman's letter to the Patient Safety Conference held in Dallas, Texas on 29 June 2000.]

spread shock waves far beyond its walls. "If this can happen at a place like Dana-Farber," one anguished medical expert asked, "what is happening in other places?"17 A letter from Betsy Lehman's mother adapted with permission from a letter she wrote to the Patient Safety Conference held in Dallas, Texas on 29 June 2000 is shown in box 1.

The CBS News show 48 Hours soon answered that question, reporting seven cases where patients were accidentally given cisplatin instead of the less toxic chemotherapy drug carboplatin. ${ }^{18}$

The Lehman incident became, to paraphrase Kuhn, the unavoidable anomaly that finally subverted the existing tradition. The proud Boston medical community reacted with "profound shock and dismay, more than anything I've ever experienced," recalled Knox. "The reason it was not 'Circle the wagons and defend ourselves' is because it was so irrevocably bald"'(R A Knox, personal communication, 6 November 2001). 
Lehman's husband, Robert Distel, a scientist who worked at Dana-Farber, was persuaded by Knox to share what the hospital had told him. Knox also called on his extensive network of other sources. "It's very, very rare to be able to lay out in very concrete, specific detail just what happened and more or less who did what and what the result was, and to be able to document it", he said. Dana-Farber immediately took full responsibility for the mistake.

Importantly, the Globe did not stop its investigation after one article. An entire section of the paper is devoted to science and medicine, and the editor was supportive of Knox's desire to dig deeper. Boston, after all, was the hometown of Leape and the Harvard Medical Practice Study. The Globe continued to run articles examining the systemic issues underlying medical mistakes.

In September 1995 the Massachusetts Hospital Association launched a medication safety project. A year later, as the AMA was announcing its plans for a safety foundation, the Massachusetts Coalition for Prevention of Medical Errors was also forming. The coalition included professional associations, public and private agencies, researchers, insurers and consumers.

The acknowledgment by groups such as the AMA and the Boston academic medical establishment that errors were pervasive made it easier to pursue the patient safety story in ways that graphically illustrated the failure of the old paradigm to protect patients. A few examples illustrate the journalistic trend. In late 1997 a freelance journalist wrote an agonising account in the financial magazine Worth about the death of his pregnant wife and newborn son. The cause was poor care by a well known New York obstetrician practising at a respected hospital. The hospital allegedly knew of previous problems with this physician but concealed them. ${ }^{19}$ In late 1998 a cover story in USA Today, one of the nation's most widely circulated newspapers, explored the systems approach to error prevention under the headline: "Aviation's safety prescriptions land in operating rooms." ${ }^{\prime 20}$ In early 1999 the New Yorker, a magazine influential among the elite in media, business and government, ran an article in which the physician author (not an obstetrician) wrote candidly about the circumstances that caused his own unintended errors. ${ }^{21}$

Back in Boston, meanwhile, Globe investigative reporter Larry Tye received a tip about a hospital that failed to follow a Massachusetts law requiring errors to be reported to the state. This narrow legal angle, which freed the reporter from having to decide whether the error was avoidable or not, led to stories that eventually exposed how five women had died during childbirth at a suburban Boston hospital. In March 1999 a four-part series on errors written by Tye ran on the Globe's first page and led quickly to hearings in the state legislature. ${ }^{22}$ Later that year the Philadelphia Inquirer ran a similar page 1 series by reporter Andrea Gerlin.

The bankruptcy of the Allegheny Health System's Philadelphia hospitals in 1998 had provided Gerlin with a detailed account of incidents, claims, and lawsuits at Philadelphia's MCP Hospital from January 1989 to June 1998. The 300 page document, which would ordinarily be protected from legal discovery, was accidentally put into the public record by the hospital's lawyers during the court proceedings (A Gerlin, personal communication, 2001).

Taking advantage of this rare good fortune, Gerlin showed the records to knowledgeable academic researchers. They told her that the hospital's experience was typical. Recalling Leape's enduring sound bite about crashing 747s, Gerlin realised that the document constituted a veritable "passenger manifest" of one hospital's casualties. She spent the next 6 months reporting and writing a four-part series that was published in the Inquirer in September 1999. The series was reprinted by more than 20 other newspapers around the country, often with a sidebar about medical errors in the local community. The articles, recalled Gerlin, "showed how doctors had numerous incentives to cover up their mistakes and few to report them".

On 29 November 1999 the Institute of Medicine released its report "To err is human" which concluded that 48 000-98000 Americans die in hospitals every year because of preventable medical errors. ${ }^{23}$ Academics saw a report largely based on the Harvard research published years earlier. From a media perspective, however, the safety story had changed. The first paragraph of the first page included brief references to three actual patients who had been harmed by medical mistakes; Lehman's name was the first on the list. The IOM report, drawing on pioneering news media coverage of errors, changed the story from a dry statistical recitation of "lots of people die" to a personalised "people like you, the reader/viewer, could die". Network TV and Congressional committees quickly used the series of stories done by Tye, Gerlin, and others to find even more "real people" to provide a human side to the statistics. The IOM, meanwhile, carefully couched even the necessary statistics in sound bites, with the ever reliable "plane crash" comparison being joined by a comparison with the magnitude of drink driving deaths and deaths from breast cancer.

This public relations positioning was purposeful. Earlier that year the IOM sought the input of veteran health care reporters about what made news. The IOM wanted to produce a report that was credible, articulate, and easy to read ( $\mathrm{J}$ Corrigan, personal communication, November 2001). The impact of this strategy was heightened because this was not just one more article in a medical journal but, rather, a call to arms by "the prestigious Institute of Medicine". Finally, "To err is human" benefited from lucky timing. It came out on a slow news day when, as one network reporter noted privately, there was no "scandal" news about President Bill Clinton and Monica Lewinsky and the death watch on Russian leader Boris Yeltsin had not produced a dead Yeltsin. Journalism abhors a vacuum.

\section{"OLD" NEWS PUSHES INNOVATION}

To the surprise of the research community, "old" news became very big "new" news. Indeed, the scope and scale of the electronic and print coverage of the IOM report represented a turning point for the error prevention movement. A Kaiser Family Foundation poll taken a few weeks after the report's release found that an astonishing $51 \%$ of the public was aware of the report's conclusions. ${ }^{24}$ The public reaction, in turn, sparked other responses. Within a year of the IOM report the US General Accounting Office (an arm of Congress) had produced a report on adverse drug events; legislation to require medical error reporting was introduced in Congress; and eight state legislatures passed error related laws. As of late 2001, 15 states had mandatory adverse event reporting and five states and the District of Columbia had voluntary reporting systems.

Meanwhile, on 1 July 2001, the Joint Commission began requiring hospitals it surveys to notify patients if they were harmed by a medical error. If medical mistakes were not yet as visible as an airliner crashing, the era of near invisibility to anyone outside a small cadre of healthcare professionals was over. The profession's attitude also began to change. Instead of defensively responding that errors were unavoidable, healthcare professionals began writing about the "growing urgency" of error reduction ${ }^{25}$ and the profession's "unprecedented concern" ${ }^{26}$ At the same time, the field began moving from "blame the individual" to a more systematic safety improvement approach. Outside pressure mobilised by the drumbeat of negative publicity left the profession little choice-at least in the short run.

The IOM report highlighted both the human and financial cost of medical mistakes. Executives at General Motors and DaimlerChrysler applied the IOM figures to their own population and came up with estimates such as "one death of a DaimlerChrysler employee, dependent or retiree every other 
day". Business $\theta$ Health, a magazine written for benefits managers, entitled an article on 1 April 2000: "Do American hospitals get away with murder?" In November 2000 a coalition of Fortune 500 employers known as the Leapfrog Group launched an initiative whose centerpiece was pushing hospitals to install computerised physician order entry systems to prevent medication errors. (Technically, Leapfrog required health plans with which it contracted to require CPOE from hospitals with which they contracted. Details are available at www.leapfroggroup.org.)

In his classic work "Diffusion of innovations", Everett Rogers wrote that five characteristics hold the key to success: (1) relative advantage over what currently exists; (2) compatibility with existing values and behaviours; (3) lack of complexity; (4) the ability to be subjected to experiment ("trialability"); and (5) producing results that everyone can see ("observability") ${ }^{27}$ These rules hold true whether the proposed improvement involves providing high yielding seeds to Third World farmers or selling a new style of jeans to jaded teenagers. Rogers' rules also help to explain why the news media has played so important a role in pushing the profession into making safety a priority.

The first of Rogers' rules - that an innovation produces "relative advantage" — can be surprisingly difficult to achieve. The innovation must not only be real, it must be perceived as real. In the case of medical errors, public scandal and the concomitant fear of public shaming finally broke through professional complacency. The influence of that fear can be seen publicly in the examples cited above-the reaction to the death of Lehman and others, the IOM report's political ramifications, the Leapfrog Group efforts-but it is equally evident in private conversations. Consultants, ever attuned to what sells, understand this reality. One safety expert recently began a speech to hospital managers by showing an excerpt of a medical error story that was aired by the top rated TV news show 60 Minutes.

By contrast, consider the near complete lack of impact on patient care of two IOM reports that attracted little media attention. The important but drily worded conclusions of a report on cancer care published in early 1999 ("many patients do not receive treatments known to be effective") merited just a few paragraphs in a wire service story and about the same attention from the profession. ${ }^{28}$ Oncology publications gave it somewhat more space. Interestingly, a British charity organisation captured headlines complaining about the quality of cancer care in that country at about the same time. Unlike the IOM, the British report blamed an identifiable villain-the government - and graphically described the inadequacies as a "pig's breakfast". ${ }^{29}$

The IOM's report entitled "Crossing the quality chasm $^{\text {"30 }}$ published in March 2001 was also a media dud, surprising some IOM insiders who expected a reprise of "To err is human". Their expectations were unrealistic. Despite its soaring rhetoric about the "chasm" separating the care Americans actually receive from the care they should receive, the report contained few human interest stories, had a complicated "plot" (unlike "tens of thousands of dead patients"), and led off with a long executive summary whose core consisted of list after list of possible actions.

To put it into Rogers' context: without media coverage reinforcing their conclusions, these two reports remained, simply, reports. As a result, the "relative advantage" of responding to their conclusions was not at all apparent to many in the profession.

By comparison, the relative advantage of acting on patient safety has been firmly established. Moreover, the growing involvement in the field of organisations such as the AMA, AHA, and other professional groups has signalled the compatibility of patient safety innovation with existing values and behaviours, another Rogers criterion. In addition, a number of organisations have worked to reduce the complexity of inno- vation (by, for example, posting specific information on web sites or offering courses); have put error reduction techniques on trial (see, for instance, the work of the Boston based Institute for Healthcare Improvement and the federal government's Veterans Health Administration); and have produced "observable" results both in the formal environment of the medical literature and in the more informal environment of professional meetings. Certainly, medical journals have become more receptive to articles on patient safety as research emerges under the sponsorship of groups such as the NPSF, the Partnership for Patient Safety, and the Agency for Healthcare Research and Quality (AHRQ).

\section{A TWO EDGED SWORD}

The increased interest of the general news media in patient safety can, of course, be a two edged sword. Journalists depend heavily on "official" sources. So, when an article in the 25 July 2001 issue of JAMA (no longer edited by Lundberg) asserted that the medical error problem was overblown, it received widespread coverage. Many of the press reported it as the equal counterpoint to the IOM reports. The article by Haywood and Hofer concluded that just $6 \%$ of those who died from a medical mistake would have left the hospital alive had optimal care been provided, and that just $0.5 \%$ would have lived 3 months in good cognitive health. ${ }^{31}$ Those in the trenches of the patient safety movement (recall: the closer one is to an event, the less one is inclined to believe the press coverage) struggled to point out that the researchers reviewed only 111 deaths, of which all were adults, all were in veterans hospitals, all but one was a man, and the average age was 69 . But given the time and space limits of radio and TV journalism and much of the print media, the doubters were drowned out by the initial soundbite.

The danger that critics of the patient safety movement might turn it into just one more "he said/she said" scientific dispute is real. Without public support, scandals can blow over like a passing squall. Contrary to myth, for example, the American news media did not cause either Richard Nixon's resignation as President due to the Watergate scandal; public and Congressional reaction to media reports did. By contrast, the public and Congress reacted tepidly to news reports suggesting that President Ronald Reagan, far more popular than Nixon, broke the law and lied to Congress about arms sales to Iran.

In a similar vein, news articles in the 1970s about the prevalence of medication errors were never able to produce the sustained public outrage that would have led to change. Senate hearings on practice variation in 1984 led to a host of announced initiatives by the profession, almost all of which disappeared when media attention did. The Libby Zion case changed resident work rules, but those rules have quietly been ignored with increasing frequency, even in New York, as memories of the scandal have faded.

With public support, though, proponents of change within the profession effect real change. The evidence for that proposition comes from both the United States and other western nations where patient safety is gaining new visibility. For example, the Quality in Australian Health Care Study with its estimate that nearly $17 \%$ of hospital admissions were associated with an adverse event, ${ }^{32}$ prompted intense media attention and a public uproar that led to the immediate appointment of a government commission to address the problem. "To err is human" tapped into a similar public anxiety. A poll carried out by the NPSF in October 1997 found that 42\% of respondents had personal knowledge of a medical error that had happened either to themselves, a relative, or a friend. If the survey of roughly 1500 people accurately represented the general public, it would mean that more than 100 million Americans have experience with medical mistakes. ${ }^{33}$ Given that resonance, news stories about the medical error problem 
continue to appear worldwide, including a four-part documentary on British television "Why Doctors Make Mistakes" in late 2000;an examination by Maclean's in mid 2001 of the patient safety problem in Canada; and continuing newspaper stories in the United States in both the major national newspaper and newspapers in smaller markets such as Tacoma, Washington, and Roanoke, Virginia.

Certainly, much work remains to be done. More than 6 years after amputation of the wrong foot of a diabetic patient by a surgeon in Florida became headline news throughout the United States, a Joint Commission study concluding that "wrong site" surgery was still distressingly common was a prominent story in The Washington Post in the middle of the war on terrorism in Afghanistan. ${ }^{34}$ Highly motivated caregivers from all over the country are starting to collaborate on initiatives tackling adverse events. The impact of the collective effort is starting to show, albeit in a limited number of healthcare institutions. Without the press they would surely not have been awakened from a sleep of denial or misinformation.

The Federal government response, directing a single agency (the AHRQ) to coordinate all patient safety research, is an important step forward. The money earmarked for studies and demonstration projects on medical errors in fiscal years 2001 and 2002 represents a significant federal commitment to this issue.

\section{CONCLUSIONS}

It is difficult to admit that outside pressure is often needed to prompt us to consult our internal ethical compass, yet human nature is what it is. Among major religions, exhortations in the name of a higher authority to "do good" are invariably accompanied by warnings of dire consequences to the listener from that same higher authority if the exhortations are not heeded. Physicians are prey to the same weaknesses as everyone else.

Lawyers, politicians, and the news media have-for better or worse-often forced an insular profession to listen to the voice of the consumer. A historian of American malpractice litigation, for example, has noted that, while the malpractice system is roundly detested and feared by doctors, its real contribution to improving quality of care was to give patients a way of catching the profession's attention:

"From the public's point of view . . . halting efforts to guarantee standards among various subsets of physicians themselves proved quickly and utterly ineffectual .... The only alternative for patients was to try to hold individual practitioners, one at a time, to whatever standards they or their lawyers, one at a time, wanted to impose."135

Indeed, it took a decision by the US Supreme Court in the early 20th century to establish a patient's simple right to know in advance of an operation exactly what surgical procedure the doctor was planning to do. And, as documented by physician author Jay Katz in "The silent world of doctor and patient", it required a series of other court decisions decades later to establish a patient's right to be told an operation's potential harms as well as benefits in plain English. ${ }^{36}$

In the United States, physicians have celebrated the power of the press when it has held managed care accountable for its abuses. The role of the press in exposing physician abuses is conveniently omitted from the discussion. As David J Rothman has written, doctors are not eager to confront the "fundamental problem of professionalism in American medicine." ${ }^{37}$ When it comes to quality improvement and patient safety, practical political realities cause many within the profession who know the truth to hold their tongues. There is enough hostility to overcome without reminding recent converts to the cause of just how reluctant their conversion was.

Journalism, as has been noted, has its own flaws; the author, who has been both journalist and academic, can attest to those from personal experience. Moreover, even the best

\section{Key messages}

- Regular revelations in the medical literature about patient deaths and injuries resulting from treatment had almost no effect on the actual practice of medicine for decades.

- The best of journalists seek to assume responsibilities not normally associated with journalism, including witness, moral and intellectual arbiter, agents of social redemption or social cohesion, if only as society's "rememberers". Until journalists "remembered" patient safety, it was an issue that society had forgotten

- The public shaming of the profession that has occurred as a result of stories about medical errors in the news media has played a key role in making adoption of innovations in error prevention of "relative advantage" to doctors and hospitals.

- While continued journalistic pressure remains important there is a growing cadre of professionals passionately committed to safety and quality improvement and willing to work either within the system or outside it.

journalists are limited by the medium in which they operate. There are space constraints-even a brilliant 60 second television piece cannot capture the complexity of a 3000 word magazine article. There are time constraints-a story that has to be reported and written in a few hours will seem shallow to the specialist who has spent a lifetime investigating the subtleties of the subject.

Still, in "The virtuous journalist", Kirkhorn suggests that journalists will continue to serve a vital societal role that other groups cannot. Many of the traditional centres of authority in society have become "repositories of special information" and have lost touch with the public. The press, he says, can link "specialized center with specialized center, public with public ... deeply and intellectually and morally and emotionally, as well as factually".

Fortunately for the public, today's healthcare journalists as a group are more sophisticated than ever. Despite journalism's inherent limits, the press remains uniquely situated to act as a watchdog to hold the medical profession accountable for improved safety and quality of care. Fortunate for the public, too, is the growing cadre of professionals passionately committed to safety and quality improvement and willing to work either within the system or outside it. Together one can hope that they will successfully push the healthcare system to better protect and enhance the care of patients.

\section{REFERENCES}

1 Kuhn TS. The structure of scientific revolutions. 2nd ed. Chicago: University of Chicago Press, 1970: 6

2 Millenson ML. Demanding medical excellence: Doctors and accountability in the information age. Chicago: University of Chicago Press, 1997: 52-73

3 Freidson E. Profession of medicine: a study of the sociology of applied knowledge. New York: Dodd Mead, 1970: 366.

4 Barr D. Hazards of modern diagnosis and therapy: the price we pay. JAMA 1955;159:1452-6.

5 Kirkhorn M. The virtuous journalist. The Quill 1982;70:9-23.

6 Mills DH. Medical insurance feasibility study: a technical summary. West J Med 1978;128:360-5.

7 Brennan TA, Leape LL, Laird NM, et al. The incidence of adverse events and negligence in hospitalized patients: results of the Harvard Medical Practice Study, I. N Engl J Med 1991;324:370-6

8 Leape LL. Error in medicine. JAMA 1994;272:1851-7.

9 Blumenthal D. Making medical errors into 'medical treasures.' JAMA 1994: 272:1867-8

10 Lundberg GD, Stacey J. Severed trust: why American medicine hasn't been fixed. New York: Basic Books, 2000: 169-72.

11 Davis L. Fellowship of surgeons: a history of the American College of Surgeons. Springfield, III.: Thomas Press, 1960.

12 McAfee RE. Malpractice system needs reform. Letter in "Voices of the People". Chicago Tribune 12 May 1995, section 1, 27.

13 American Medical Association. Report of the board of trustees on medication errors in hospitals. Submitted to the AMA House of Delegates at the AMA annual meeting, Chicago, June 1994.

14 Prager LO. Safety-centered care. American Medical News 13 May 1996,1 
15 Maurer H. The MDs are off their pedestal. Fortune February 1954, 139-86.

16 Guadagnino C. Improving anesthesia safety. Physician's News Digest February 2000. Accessed at: www. physiciansnews.com/spotlight/ 200wp.html.

17 Knox RA. Doctor's orders killed cancer patient. Boston Globe 23 March 1995, section 1, 1.

18 CBS News. Is your hospital safe? 48 Hours 14 September 1995

19 Grossman E. The best medicine. Worth 1997:6:98-122.

20 Davis R. Medicine's flying lessons: aviation's safety prescriptions land in operating rooms. USA Today 19 October 1998, D-1.

21 Gawande A. When doctors make mistakes. New Yorker $1999 ; 74: 40-55$

22 Tye L. Patients at risk: hospital errors. Boston Globe March 1999.

23 Institute of Medicine. To err is human: Building a safer health system. Washington, DC: National Academy Press, 1999.

24 Kaiser/Harvard Health News Index 1999;4 (available at http://www.kff.org/content/2000/1565/HNI\%20Nov-Dec 1999.pdf).

25 O'Leary D. Accreditation's role in reducing medical errors. West J Med 2000; 172:357-8.

26 Thomas E. Commentary: some interventions are effective in reducing medical errors. ACP Journal Club 2001;135:115.

27 Rogers EM. Diffusion of innovations. 3rd ed. Detroit: Free Press, 1983 $1 ; 14-15$.

28 National Cancer Policy Board, Institute of Medicine and Commission on Life Sciences, National Research Council. Ensuring quality cancer care. Washington, DC: National Academy Press, 1999: 1-6.

29 BBC News. Cancer care: 'a pig's breakfast'. 23 April 1999. http://news.bbc.co.uk/hi/english/health/newsid_327000/ 327062.stm.

30 Institute of Medicine. Crossing the quality chasm: A new health system for the 21 st century. Washington, DC: National Academy Press, 2001.

31 Hayward RA, Hofer TP. Hospital deaths due to medical errors: estimating preventability is in the eye of the reviewer. JAMA 2001;286:415-20.

32 Wilson RM, Runciman WB, Gibberd RW, et al. The Quality in Australian Health Care Study. Med J Aust 1995;163:458-71.

33 Chamberlin C. Medical mistakes affect many: poll finds widespread error. $A B C$ News 9 October 1997 (available at http:// abcnews.go.com/sections/living/DailyNews/medmistakes 1009.html). The poll angered the AMA House of Delegates and it is no longer to be found on the AMA web site.

34 Brown D. Surgical calamities on the rise, group says. Reports of doctors operating on wrong body part-or patient-have increased. Washington Post 6 December 2001, A14.

35 Mohr JC. American medical malpractice litigation in historical perspective. JAMA 2000;283:1731-7.

36 Katz J. The silent world of doctor and patient. New York: Free Press, 1984

37 Rothman DJ. Medical professionalism: focusing on the real issues. $N$ Engl J Med 2000;342: 1 284-6

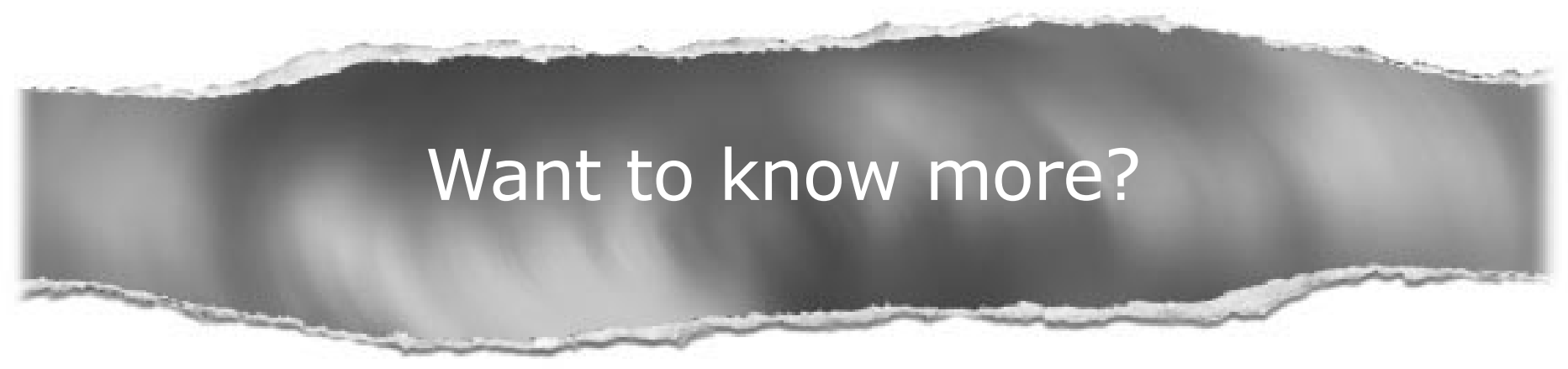

Data supplements

Limited space in printed journals means that interesting data and other material are often edited out of articles; however, limitless cyberspace means that we can include this information online.

Look out for additional tables, references, illustrations.

www.qualityhealthcare.com 